\title{
THE NEBULAR SPECTRA OF TWO SLOW NOVAE DQ HERCULIS AND RT SERPENTIS*
}

\author{
P. SWINGS† AND O. STRUVE
}

\begin{abstract}
The spectrum of Nova Herculis has been measured in the region $\lambda \lambda 3200-6700$, and many new lines have been identified. The character of the spectrum has not changed greatly since the observations by Adams and Joy in I935-1936, but the increased separation between the two visual components of the Nova has now made it possible to observe separately the two spectra. The ionization seems to be identically the same in the two objects, but some differences in the structure of the lines was noticed. Spectra taken with the slit along the major axis of the elongated image show a marked depression between the two outside components of the emission lines, while at least the preceding component of the binary shows a fairly strong central component between the two outside components. The observations are sensitive to conditions of seeing, and it is not possible at this stage to unravel the true nature of the spectroscopic structure of the lines.

The spectrum of Nova Serpentis, which had an outburst in I 909 and which is known to have developed abnormally slowly, was last described by Joy in I93I. Since that time the spectrum has undergone marked changes: the lines of $[F e$ III] $]$, which were strong in I93I, are very weak on our spectrogram. Instead, $[N \in \mathrm{III}],[N e \mathrm{~V}]$, and [Fe vI] are strong, in addition to $H, H e \mathrm{I}, H e \mathrm{II}$, and [O III]
\end{abstract}

Nova DQ Herculis, I934, ${ }^{\mathrm{I}}$ is a typical representative of the slowly developing type of novae, while the evolution of Nova RT Serpentis, $1909,{ }^{2}$ is usually regarded as having been quite abnormally slow. Former observations of Nova Herculis have shown that the bright lines have a complex structure, and the suggestion has been made by Whipple and Payne-Gaposchkin ${ }^{3}$ that this structure may be related to the duplicity of the object discovered by Kuiper. It is important to examine the present structure of the lines after several years have elapsed since the outburst. In addition, we have investigated the

* Contributions from the McDonald Observatory, University of Texas, No. 25.

$\dagger$ Visiting scientist of the Belgian-American Foundation and visiting astronomer at the Yerkes Observatory.

I Adams and Joy, Ap. J., 84, I4, I936; McLaughlin, Pub. Obs. U. Michigan, 6, I07, г937; Dufay, Zs.f.Ap., г3, 36, r936; Vorontsov-Velyaminov, Zs.f. Ap., I I, I45, г935; Beer, M.N., 96, 236, г936; Popper, Pub. A.S.P., 51, г68, г939.

${ }^{2}$ Joy, Pub. A.S.P., 43, 353, I931.

3 Proc. Nat. Acad. Sci., 22, 195, 1936. Attention is also called to a suggestion by Morgan ( $A$ p. $J ., 83,252$, I936) that two sets of absorption lines observed in January, I935, may have been produced by the two components. 
ultraviolet region of the spectrum which has not previously been described in detail.

The spectrum of Nova Serpentis, when last observed by Joy in I93I, was characterized by a strong group of bright lines at $\lambda \lambda{ }_{4} 658$, 4701, and 4733, which has recently been attributed to forbidden [Fe III] by Edlén and Swings. ${ }^{4}$ Since the evolution of this nova has been very slow, it would be reasonable to expect that after an interval of some nine years the spectrum would show some higher stage of ionization of iron, such as was found after a relatively short course of development in Nova Pictoris, Nova Herculis, and Nova Lacertae, I936.

Fifteen spectrograms of Nova Herculis were secured at the McDonald Observatory between April I9 and May I3, I940, with dispersions of $100 \mathrm{~A} / \mathrm{mm}$ (quartz prisms and $\mathrm{f} / 2$ camera), $50 \mathrm{~A} / \mathrm{mm}$ (glass prisms and $\mathrm{f} / 2$ camera), and $40 \mathrm{~A} / \mathrm{mm}$ (quartz prisms and $\mathrm{f} / 5$ camera) at $\lambda$ 3933. One spectrogram of Nova Serpentis ${ }^{5}$ was obtained on May 3, I940, with a dispersion of $200 \mathrm{~A} / \mathrm{mm}$ at $\lambda 3933$ (quartz prisms and $\mathrm{f} / \mathrm{I}$ camera). The star was then approximately of magnitude I4.0.

The results of the measurements of all the spectrograms of $\mathrm{N}$ Her are collected in Table I. The wave lengths have been corrected for the motion of the earth but not for the stellar velocity. Almost all lines are satisfactorily identified. The Balmer series is observed to $H_{\mathrm{I} 7}$ and is followed by a strong continuum. Many $\mathrm{He} \mathrm{I}$ lines are present, the strongest unblended series being $2 \mathrm{p}^{3} \mathrm{P}^{\circ}-3,4,5,6 \mathrm{~d}^{3} \mathrm{D}$. The series $4 \mathrm{f}^{2} \mathrm{~F}^{0}-\mathrm{ng}^{2} \mathrm{G}$ of $H e \mathrm{II}$ has been observed to $n=\mathrm{I} 7$. Weak lines of $C$ II, $C$ III, and $C$ IV are present; the excitation of these lines is certainly not due to some fluorescence mechanism of the type found by Bowen for $O$ III and $N$ III. Several lines of $N$ II are observed (lab. int. from 5 to Io; stellar int. from o to 3 ), for which no fluorescence mechanism is responsible. The $N$ III spectrum is strong, and Bowen's mechanism, if present, is not the only one which operates, since $\lambda$ 4379, which cannot be excited by fluorescence, is present. $O \mathrm{II}$ is weak; possibly also $O \mathrm{IV}$. $O \mathrm{III}$ is strong, and its excita-

4 Observatory, 62, 234, 1939.

5 A map of the region of RT Ser was published by Barnard, Pop. Astr., 27, 374, I9 9. 
TABLE 1

THE SPECTRUM OF N HeR

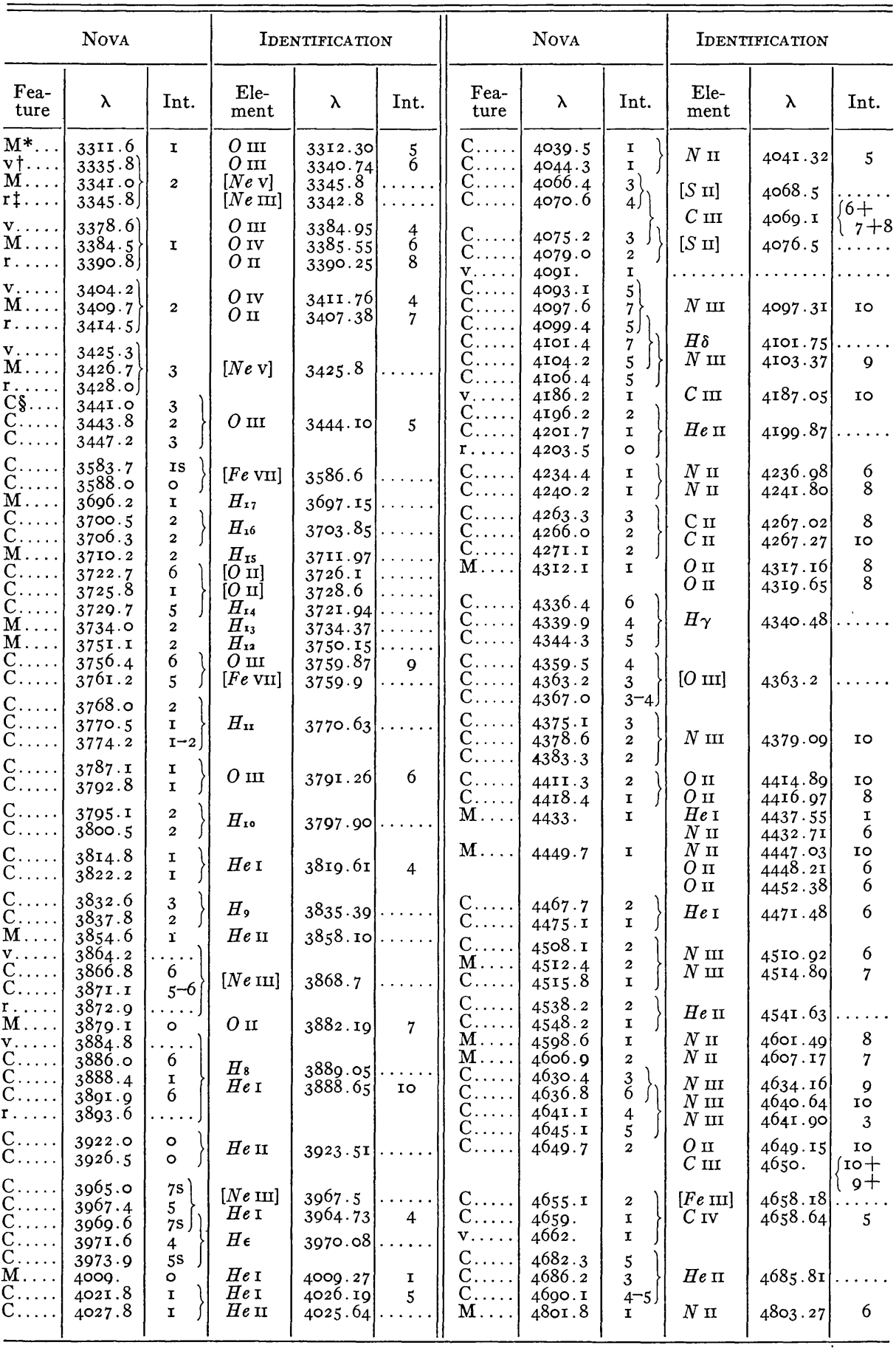

* $\mathrm{M}=$ maximum intensity of the band

$\dagger \mathrm{v}=$ violet edge. $\ddagger \mathrm{r}=$ red edge

$\S \mathrm{C}=$ component. 
TABLE 1-Continued

\begin{tabular}{|c|c|c|c|c|c|c|c|c|c|c|c|}
\hline \multicolumn{3}{|c|}{ Nova } & \multicolumn{3}{|c|}{ IDENTIFICATION } & \multicolumn{3}{|c|}{ Nova } & \multicolumn{3}{|c|}{ IDENTIFICATION } \\
\hline $\begin{array}{l}\text { Fea- } \\
\text { ture }\end{array}$ & $\lambda$ & Int. & $\begin{array}{l}\text { Ele- } \\
\text { ment }\end{array}$ & $\lambda$ & Int. & $\begin{array}{l}\text { Fea- } \\
\text { ture }\end{array}$ & $\lambda$ & Int. & $\begin{array}{l}\text { Ele- } \\
\text { ment }\end{array}$ & $\lambda$ & Int. \\
\hline $\begin{array}{l}\mathrm{C} \ldots \ldots \\
\mathrm{C} \ldots \ldots \\
\mathrm{C} \ldots \ldots \\
\mathrm{M} \ldots \ldots \\
\mathrm{C} \ldots \ldots \\
\mathrm{C} \ldots \ldots \\
\mathrm{C} \ldots \ldots \\
\mathrm{C} \ldots \ldots \\
\mathrm{C} \ldots \ldots \\
\mathrm{C} \ldots \ldots \\
\mathrm{M} \ldots \ldots \\
\mathrm{M} \ldots \ldots\end{array}$ & $\begin{array}{l}4856.9 \\
4861.3 \\
4865.9 \\
4920.3 \\
4954.0 \\
4958.3 \\
4962.6 \\
5004.1 \\
5006.5 \\
5010.0 \\
5175 \cdot 3 \\
5197.6 \\
5275.0 \\
5412 . \\
5532 .\end{array}$ & $\begin{array}{r}8 \\
6 \\
7 \\
1 \\
\text { I5 } \\
10 \\
15 \\
25 \\
20 \\
25 \\
1 \\
2\end{array}$ & $\begin{array}{l}H \beta \\
H e \mathrm{I} \\
{[O \mathrm{III}]} \\
\\
{[O \mathrm{III}]} \\
{[F e \mathrm{VI}]} \\
{[N \mathrm{I}]} \\
{[N \mathrm{I}]} \\
{[F e \text { VII }]} \\
H e \text { II } \\
N \text { II }\end{array}$ & $\begin{array}{l}486 \mathrm{I} \cdot 34 \\
492 \mathrm{I} \cdot 93 \\
4958 \cdot 9 \mathrm{I} \\
\\
5006 \cdot 84 \\
\\
5 \mathrm{I} 77 \cdot 0 \\
5 \mathrm{I} 98 \cdot 5 \\
5200 \cdot 7 \\
5276 \cdot \mathrm{I} \\
54 \mathrm{II} \cdot 57 \\
5535 \cdot 39\end{array}$ & $\begin{array}{l}\cdots \cdots \\
\cdots \ldots \\
\cdots \cdots \\
\cdots \cdots \\
\cdots \cdots \\
{ }_{5}\end{array}$ & 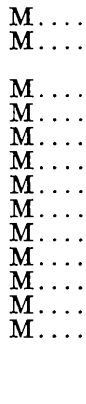 & $\begin{array}{l}5599.4 \\
5678.6 \\
\\
5755.5 \\
5796.3 \\
5876 . \\
5913 . \\
5941 . \\
6088 . \\
6300 . \\
6364 . \\
6549 . \\
6564 . \\
6584 .\end{array}$ & $\begin{array}{r}2 \\
3 \\
6 \\
1 \\
4 \\
1 \\
2 \\
1 \\
5 \\
3 \\
9 \\
10 \\
12\end{array}$ & 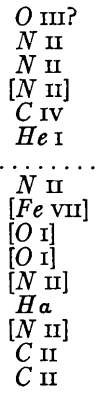 & $\begin{array}{l}5592 \cdot 37 \\
5679 \cdot 56 \\
5666.64 \\
5755 \cdot 0 \\
5801 \cdot 5 \\
5875 \cdot 62 \\
\ldots \ldots \ldots .6 \\
5941.67 \\
6089 . \\
6300 \cdot 2 \\
6363.9 \\
6548 \cdot 4 \\
6562.82 \\
6583 \cdot 9 \\
6582.85 \\
6578.03\end{array}$ & $\begin{array}{c}6 \\
\text { 10 } \\
8 \\
\cdots \cdots \\
4 \\
\text { 10 } \\
\cdots \\
8 \\
\cdots \\
\cdots \cdots \\
\cdots \cdots \\
\cdots \cdots \\
\cdots \cdots \\
\cdots \cdots \\
8 \\
\text { 10 }\end{array}$ \\
\hline
\end{tabular}

tion may be due mainly to Bowen's process. The forbidden lines in order of decreasing intensity are $[O \mathrm{III}]$ (giving something like 95 per cent of the total light of the object), $[N e \mathrm{III}],[N \mathrm{II}],[O \mathrm{I}],[S \mathrm{II}]$, $[N e \mathrm{v}]$, and $[\mathrm{OI}]$. There are indications of $[\mathrm{Fe} \mathrm{III}],[\mathrm{Fe} \mathrm{vI}],[\mathrm{Fe} \mathrm{vII}]$, and $[N \mathrm{I}]$.

There has been no great change in the spectrum since the observations by Adams and Joy. But the structure of the lines is different.

Besides the bright lines, the spectrograms show a faint continuous spectrum with maximum near $\lambda_{4} \mathrm{I}_{50} \mathrm{O}$; the intensity of this spectrum corresponds to a star of magnitude between 13 and I4. There is some suspicion of broad absorption features, the strongest of which is to the red of the emission band at $\lambda{ }_{4200}$. However, it is difficult to distinguish between true absorption features and spaces between emission bands.

The unblended emission lines consist of two symmetrical components. On some of the best plates there is a third, central, component between them. The spaces between the components are filled in with weaker emission.

With the large scale of the Cassegrain combination ( $7 " 4$ per mm) the nova, though not completely resolved on the slit, shows a markedly elongated image, and in good seeing the two visual components may be observed separately by placing the slit at right angles to the major axis of the ellipse and by guiding accurately on the preceding 
or on the following tip of the elongated image. Several spectrograms were obtained in this manner, while for others the slit was placed along the major axis of the ellipse.

The two visual components have very similar spectra. The lines and their relative intensities are identical. However, the structure of the lines shows some slight differences. On the night of April 25, in excellent seeing, the preceding tip of the elongated image showed strong central lines with weak outside components. On the same night the following tip showed little, if any, structure within the broad emission bands. Several plates taken with the slit along the major axis of the ellipse show a marked depression between the two outside lines.

The observations are sensitive to conditions of seeing, and the dispersion is barely sufficient to show the triple structure. We are not quite certain whether the difference between the preceding and the following tip is real, but there can be no doubt about the difference between the preceding tip and the integrated spectrum taken along the major axis. Nor can there be much doubt that the following tip gives nearly equally strong outside components.

This latter result contradicts the conclusion of Whipple and Payne-Gaposchkin: "There can be little doubt that the red and violet components of the doubled emission lines correspond respectively to the fainter and brighter components of the nova observed visually." Incidentally this view has been criticized by McLaughlin, ${ }^{7}$ who states:

Such an apparent duplicity of the emission bands has characterized every well observed nova of the twentieth century, regardless of the uniformity or the knottiness of the nebulosity ejected by it. In the case of Nova Persei, the southern bright fan-shaped knot now gives both approaching and receding velocities.

The continuous spectrum probably corresponds to a star of very early type, and it seems safe to attribute it to the hot nucleus which excites the nebular radiation.

Only the unblended lines showing the triple structure may be used for radial-velocity determinations. The central component is quite indistinct for many lines. The results are collected in Table 2.

${ }^{6}$ Loc. cit. $\quad$ 7 Op. cit., p. 209. 
The last published determination is by Stratton; $;$ it was based on $N_{\text {I }}$ observed on August I7, I939; his values are $-280,-50$, and $+240 \mathrm{~km} / \mathrm{sec}$.

The continuous spectrum of RT Serpentis is extremely weak and does not contribute appreciably to the brightness of the object. The measured bright lines are collected in Table 3. They have been corrected for the earth's motion but not for the stellar velocity.

Besides $\mathrm{Ha}$, the strongest line is [Ne III] 3869; the [Ne III] lines were also exceptionally strong in several other novae, viz., $\mathrm{N}$ Persei,

TABLE 2

Radial VeLocities of N HeR IN KM/SeC

\begin{tabular}{|c|c|c|c|c|}
\hline Element & $\lambda$ Lab. & $\begin{array}{c}\text { Violet } \\
\text { Component }\end{array}$ & $\begin{array}{c}\text { Central } \\
\text { Component }\end{array}$ & $\begin{array}{c}\text { Red } \\
\text { Component }\end{array}$ \\
\hline 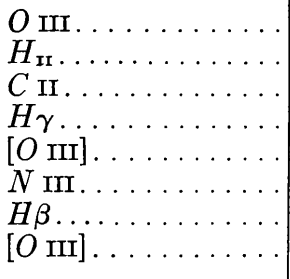 & $\begin{array}{l}3444 \cdot 10 \\
3770.63 \\
4267 \cdot 2 \\
4340.48 \\
4363 \cdot 2 \\
4379.09 \\
4861.34 \\
4958.91\end{array}$ & $\begin{array}{l}-269 \cdot 7 \\
-209 \cdot 1 \\
-274.2 \\
-281.9 \\
-254.2 \\
-273.3 \\
-273.9 \\
-297.0\end{array}$ & $\begin{array}{l}-26.1 \\
-10.3 \\
-84.4 \\
-40.1 \\
0 \\
-33.6 \\
-\quad 2.5 \\
-36.9\end{array}$ & $\begin{array}{l}+269.7 \\
+283.8 \\
+274.2 \\
+264.0 \\
+261.1 \\
+288.4 \\
+281.3 \\
+223.2\end{array}$ \\
\hline $\begin{array}{r}\text { Mean (assum- } \\
\text { ing weight } 3 \\
\text { for } H \gamma) \ldots\end{array}$ & & -269.7 & -3 I. 4 & +267.4 \\
\hline
\end{tabular}

I90I, and N Sagittarii, I936. The absence of $O$ III lines shows that the observed $N$ III lines are not excited by fluorescence. There is no trace of lines due to carbon ions, and the permitted oxygen lines, if present, are extremely weak; there is no trace of $[O \mathrm{II}]$. The $[\mathrm{Fe} \mathrm{III}]$ lines which were outstanding in I93I are now very weak, the strongest transition, $\lambda{ }_{4} 658.18,{ }^{5} \mathrm{D}_{4}-{ }^{3} \mathrm{~F}_{4}$, having only intensity I on our spectrogram. The evidence for the presence of $[F e \mathrm{v}]$ is based mainly on a weak extension of $H_{9}\left(\lambda_{3} 835.39\right)$ toward the red; one of the strongest $[\mathrm{Fe} \mathrm{v}]$ lines, ${ }^{5} \mathrm{D}_{3}-{ }^{3} \mathrm{~F}_{3}$, has the wave length 3838.9 . The strongest $[\mathrm{Fe} \mathrm{v}]$ line to be expected, ${ }^{5} \mathrm{D}_{4}-{ }^{3} \mathrm{~F}_{4}$, at $\lambda_{389}$ I. 8 is blended with $H_{8}$ and $H e \mathrm{I} \lambda 3888.65$. The evidence in favor of the ${ }^{4} \mathrm{~F}-{ }^{2} \mathrm{G}$ forbidden transition of $[\mathrm{Fe} \mathrm{VI}]$ is conclusive. On our spectrogram

${ }^{8}$ Observatory, 62, 236, I939. 
TWO SLOW NOVAE

TABLE 3

THE SPECTRUM OF N SER

\begin{tabular}{|c|c|c|c|c|c|c|c|c|c|c|c|}
\hline \multicolumn{2}{|c|}{ Nova } & \multicolumn{3}{|c|}{ IDENTIFICATION } & \multirow{2}{*}{ Notes } & \multicolumn{2}{|l|}{ Nova } & \multicolumn{3}{|c|}{ IDENTIFICATION } & \multirow{2}{*}{ Notes } \\
\hline$\lambda$ & Int. & Element & $\lambda$ & Int. & & $\lambda$ & Int. & Element & $\lambda$ & Int. & \\
\hline $\begin{array}{l}3427 \cdot 2 \ldots \\
3839 \cdot 5 \ldots \\
3870.1 \ldots \\
3892.0 \ldots \\
\\
\\
3968.6 \ldots \\
4011.4 \ldots \\
4026.2 \ldots \\
4072.1 \ldots \\
4080.0 \ldots \\
4102.0 \ldots \\
4103 \cdot 9 \ldots \\
4142.9 \ldots \\
4172.9 \ldots \\
4199.2 \ldots \\
4342.0 \ldots \\
4354 \cdot 3 \ldots \\
4366.0 \ldots \\
4473.0 \ldots \\
4540.8 \ldots \\
4587.1 \ldots \\
4638.2 \ldots\end{array}$ & $\begin{array}{l}7 \\
0 \\
I \\
2 \\
0 \\
2 \\
5 \\
\\
\text { I } \\
\text { I } \\
\text { I } \\
6 \\
2 \\
6 \\
2 \\
2 \\
1 \\
3\end{array}$ & 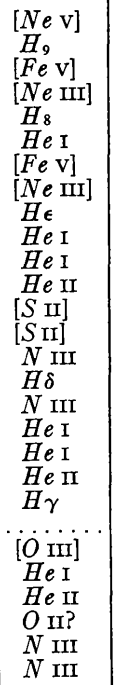 & $\begin{array}{l}3425 \cdot 8 \\
3835 \cdot 39 \\
3838 \cdot 9 \\
3868 \cdot 7 \\
3889 \cdot 05 \\
3888 \cdot 65 \\
3891 \cdot 8 \\
3967 \cdot 5 \\
3970 \cdot 08 \\
4009 \cdot 27 \\
4026 \cdot 19 \\
4025 \cdot 64 \\
4068 \cdot 5 \\
4076 \cdot 5 \\
4097 \cdot 3 \\
4101 \cdot 75 \\
4103 \cdot 37 \\
4143 \cdot 77 \\
4168 \cdot 97 \\
4199 \cdot 87 \\
4340 \cdot 48 \\
\ldots . \cdots \\
4363 \cdot 2 \\
4471 \cdot 48 \\
4541.63 \\
4590 \cdot 98 \\
4634 \cdot 16 \\
4640.64\end{array}$ & 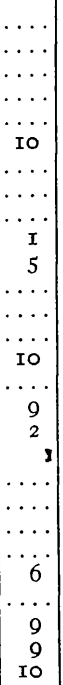 & 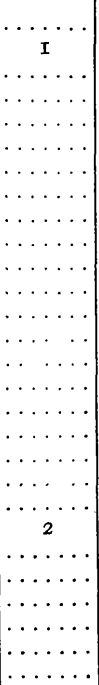 & 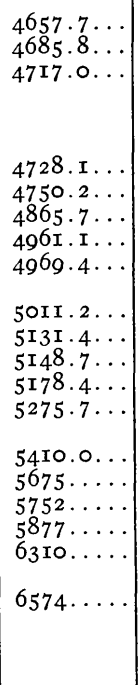 & $\begin{array}{l}2 \\
2 \\
8 \\
3 \\
2 \\
7 \\
7 \\
1 \\
2 \\
2 \\
0 \\
2 \\
2 \\
0 \\
2 \\
3 \\
2\end{array}$ & 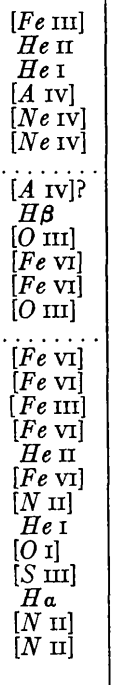 & 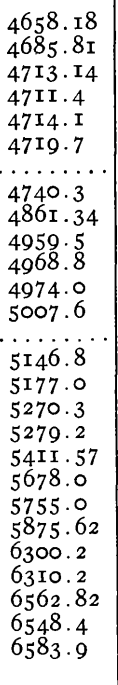 & 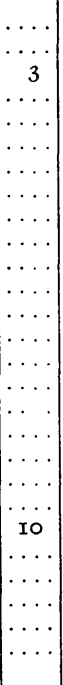 & 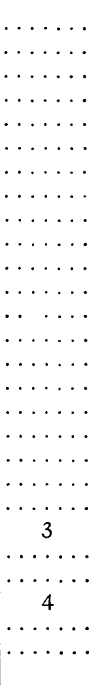 \\
\hline
\end{tabular}

\section{NOTES TO TABLE 3}

I. The line has an extension to the red.

2. This line is probably not due to $[F e \mathrm{II}]$, as the other $[F e \mathrm{II}]$ lines are absent.

3. There is a broad feature from $\lambda 6025$ to $\lambda 6 \mathrm{I} 76$.

4. The line is broad and is certainly due to both $\mathrm{H} a$ and [ $N$ II].

TABLE 4

RADIAL VELOCITIES OF N SER IN KM/SEC

\begin{tabular}{|c|c|c|}
\hline Element & $\lambda$ Lab. & $\begin{array}{c}\text { Radial } \\
\text { Velocity }\end{array}$ \\
\hline $\begin{array}{l}{[\mathrm{Ne} e \mathrm{~V}] \ldots \ldots} \\
{[\mathrm{Ne} \text { III }] \ldots \ldots \ldots} \\
\mathrm{H} \gamma \ldots \ldots \\
\mathrm{H}{ }_{\mathrm{H}} \mathrm{I} \ldots \ldots \ldots \ldots\end{array}$ & $\begin{array}{l}3425.8 \\
3868 \cdot 7 \\
4340 \cdot 48 \\
4471.48\end{array}$ & $\begin{array}{l}\mathrm{km} / \mathrm{sec} \\
+\mathrm{r} 24 \\
+\mathrm{r} 10 \\
+\mathrm{Ir} 4 \\
+\mathrm{r} 00\end{array}$ \\
\hline Mean.... & $\ldots \ldots \ldots$ & +II2 \\
\hline
\end{tabular}


there is a fairly broad feature extending from $\lambda 6025$ to $\lambda 6176$; this may contain the strongest [Fe VII] line $\lambda 6089$.

Because of the low dispersion, no accurate determination of the radial velocity of $\mathrm{RT}$ Serpentis is possible. The most reliable measures are collected in Table 4.

In I93 I the radial velocity determined by Joy from the known bright lines was $+92.3 \mathrm{~km} / \mathrm{sec}$.

In both objects the forbidden lines of [Ne III], [Ne v], [Fe III], and $[F e \mathrm{vI}]$ are present. If we assume that the relative abundance of neon and oxygen is the same in the two objects, the greater intensity of $[N e \mathrm{III}]$ in $\mathrm{N}$ Ser, compared to $[O \mathrm{III}]$, indicates that the excitation conditions observed at present are slightly higher in $\mathrm{N}$ Ser; the ionization potentials of $\mathrm{O}^{+}$and $\mathrm{Ne}^{+}$are 34.9 and 40.9 volts, respectively. This agrees also with the observed intensities of $[O \mathrm{II}]$ (absent in $\mathrm{N}$ Ser and strong in N Her) and of [S II] (weak in N Ser and strong in $\mathrm{N}$ Her).

Macdonald Observatory

May I8, I940 